\title{
Serum pepsinogen levels and their influencing factors: A population-based study in 6990 Chinese from North China
}

\author{
Li-Ping Sun, Yue-Hua Gong, Lan Wang, Yuan Yuan
}

\author{
Li-Ping Sun, Yue-Hua Gong, Lan Wang, Yuan Yuan, Cancer \\ Institute, First Affiliated Hospital, China Medical University, \\ Shenyang 110001, Liaoning Province, China \\ Supported by National Key Technologies R\&D Program of \\ China during the 10th Five-year Plan Period, No. 2001BA703B06 \\ (B), 2004BA703B04-02 \\ Correspondence to: Dr. Yuan Yuan, Cancer Institute, First \\ Affiliated Hospital, China Medical University, 155 Nanjing North \\ Street, Shenyang 110001, Liaoning Province, \\ China.yyuan@mail.cmu.edu.cn \\ Telephone: +86-24-83282153 Fax: +86-24-83282292 \\ Received: June 11, 2007 Revise: October 9, 2007
}

\begin{abstract}
AIM: To explore the essential characteristics of serum pepsinogen (PG) levels in Chinese people, by analyzing the population-based data on the serum levels of PG I and II and the PG I / II ratio, and their influencing factors in Chinese from North China.

METHODS: A total of 6990 subjects, who underwent a gastric cancer screening in North China from 1997 to 2002, were collected in this study. Serum pepsinogen levels were measured by enzyme-linked immunosorbent assay (ELISA). $H$ pylori status was determined by histological examination and $H$ pylori-IgG ELISA. The cut-off point was calculated by using receiving operator characteristics (ROC) curves. Factors linked to serum PG I / II ratio were identified using a multivariate logistic regression.
\end{abstract}

RESULTS: The serum PG I and PG II levels were significantly higher in males than in females $(95.2$ $\mu \mathrm{g} / \mathrm{L} v s 79.7 \mu \mathrm{g} / \mathrm{L}, P<0.01 ; 12.1 \mu \mathrm{g} / \mathrm{L} v s 9.4 \mu \mathrm{g} / \mathrm{L}$, $P<0.01)$, PG I / II ratio was significantly lower in males than in females ( 7.9 vs 8.3, $P<0.01$ ). The PG I / II ratio decreased significantly in the aged groups following the progression of gastric mucosa from normal to non-atrophic and atrophic lesions (10.4, 8.8, and 6.6 , respectively). The serum PG I and II levels were significantly higher in patients with $H$ pylori infection than in those without $H$ pylori infection $(88.7 \mu \mathrm{g} / \mathrm{L}$ vs 81.4 $\mu \mathrm{g} / \mathrm{L}, P<0.01 ; 11.4 \mu \mathrm{g} / \mathrm{L} v s 8.4 \mu \mathrm{g} / \mathrm{L}, P<0.01$ ), while the PG I / II ratio was significantly lower in patients with $H$ pylori infection than in those without $H$ pylori infection (7.7 vs 9.6, $P<0.01$ ). For patients with atrophic lesions, the area under the PG I / II ROC curve was 0.622. The best cut-off point for PG I / II was 6.9, with a sensitivity of $53.2 \%$, and a specificity of $67.5 \%$. Factors linked to PG
I / II were sensitive to identified PG using a multinomial logistic regression relying on the following inputs: males (OR: $1.151,95 \% \mathrm{CI}: 1.042-1.272, P=0.006)$, age $\geqslant$ 61 years (OR: $1.358,95 \% \mathrm{CI}: 1.188-1.553, P=0.000$ ), atrophic lesion (OR: 2.075, 95\% CI: $1.870-2.302, P$ $=0.000$ ), and $H$ pylori infection (OR: $1.546,95 \% \mathrm{CI}$ : $1.368-1.748, P=0.000)$.

CONCLUSION: The essential characteristics of serum PG levels in Chinese are significantly skewed from the normal distribution, and influenced by age, sex, gastric mucosa lesions and $H$ pylori infection. PG I / II ratio is more suitable for identifying subgroups with different influence factors compared with PG I or PG II alone.

\section{(c) 2007 WJG. All rights reserved.}

Key words: Pepsinogen; Gastric cancer; Helicobacter pylori; Screening

Sun LP, Gong YH, Wang L, Yuan Y. Serum pepsinogen levels and their influencing factors: A population-based study in 6990 Chinese from North China. World J Gastroenterol 2007; 13(48): 6562-6567

$$
\text { http://www.wjgnet.com/1007-9327/13/6562.asp }
$$

\section{INTRODUCTION}

Human pepsinogens (PGs) are inactive pro-enzymes for the specific digestive enzyme--pepsin originating from the gastric mucosa, and can be classified biochemically and immunochemically into pepsinogen I (PG I) and pepsinogen II (PGII). Both of them are secreted by the chief and mucous neck cells of the gastric fundus and corpus. PG II is also secreted by the pylori glands in the antrum and Brunner's glands in the proximal duodenum. PG I and PG II are secreted into the gastric lumen and $1 \%$ of them are also leaked into circulating blood $^{[1,2]}$. PG levels in blood seem to be related to the morphologic and functional changes in the stomach, and their use as 'serological biopsy' has been reported over 20 years before ${ }^{[3-5]}$. Recently, more and more investigators are concerned about the relationship between serum PG levels and gastric precancerous diseases, gastric carcinogenesis, and the significance of them being a marker for the screening of gastric cancer (GC). In most Western countries, the focus has been on the 
identification of individuals for intervention studies, whereas in Japan the use of PG levels is to identify those for endoscopic examination and those at risk for $G C^{[6-10]}$. However, the limited knowledge about their characteristics in different populations and the significant differences in methodologies may prejudice the assessment of consistency. For instance, different cut-off values are used for the positive definition when either PG I levels or both PG I and PG II levels are considered ${ }^{[11-13]}$. Furthermore, due to few cohort studies have been done in Chinese, the population-based data on serum PG levels and their influencing factors, such as age, sex, the presence of different gastric diseases and $H$ pylori infection, are limited ${ }^{[14,15]}$.

In the present study, we measured the serum PG I , PG II levels in residents from the Zhuanghe County, Liaoning Province, in North China, in order to investigate the essential characteristicss of serum PG levels in Chinese, which is expected to provide a valuable reference for largescale surveys of gastric cancer.

\section{MATERIALS AND METHODS}

\section{Subjects}

A total of 6990 subjects ( 3455 men and 3535 women), who underwent gastric cancer screening in North China from 1997 to 2002, were enrolled in this study. Their mean age was 48.84 years, ranging 11-82 years. Information about gender, age and other factors was obtained by means of a questionnaire administered to each subject. The study was approved by the Human Ethics Review Committee of China Medical University. Written informed consent was obtained from participants in accordance with the Declaration of Helsinki and its later revision.

\section{Serum pepsinogen level}

Approximately $5 \mathrm{~mL}$ fasting blood was collected from each participant and kept at $4{ }^{\circ} \mathrm{C}$ for $24 \mathrm{~h}$. The blood was centrifuged at $3000 \mathrm{r} / \mathrm{min}$ for $10 \mathrm{~min}$ and the serum aliquot was stored immediately at $-20^{\circ} \mathrm{C}$ and then shifted to an environment at $-70^{\circ} \mathrm{C}$ for the determination of various parameters. Serum PG concentration was measured by enzyme-linked immunosorbent assay (ELISA) with PG I /PG II ELISA kits (Biohit Co., Ltd., Finland).

\section{Endoscopic and clinicopathological examinations}

Gastrointestinal endoscopy was performed for observing the entire stomach. Experienced endoscopists performed each examination without knowledge about the serological data on the study subjects. Gastric mucosa was examined, and 4 biopsy specimens were obtained from the body, angulus, antrum and lesions, respectively. The biopsies were routinely bathed in 10\% formalin, embedded in paraffin, then sectioned and stained in each local center. The stained sections were evaluated independently by two gastrointestinal pathologists. Each subject was assigned a global diagnosis based on the 4 specimens. Microscopic findings were assessed according to the consensus on chronic gastritis at the national symposium ${ }^{[16]}$ or in combination with the visual analog scale of the updated
Sydney System ${ }^{[17]}$, including normal mucosa (NOR, $n=494)$, superficial gastritis (SG, $n=3954)$, erosive gastritis and ulcers (GEU, $n=362$ ), superficial gastritis accompanying IM (SG-IM, $n=347)$, atrophic gastritis (AG, $n=870$ ), gastric polyp(GP, 73 cases), dysplasia (GD, $n=$ $110)$ and $\mathrm{GC}(n=80)$.

\section{Identification of $H$ pylori infection}

Gastric biopsies were evaluated for $H$ pylori infection by histological examination. $H$ pylori could be found in gastric epithelium or in mucus. Serum immunoglobulin (Ig) $\mathrm{G}$ antibodies to $H$ pylori were detected by ELISA with $H$ pylori-IgG ELISA kit (Biohit Co., Ltd., Finland) in duplicate. Patients whose antibody titer defined by optical density (OD)values according to the manufacturer's protocol, was higher than the cut off value of $42 \mathrm{EIU}$, were regarded as positive for $H$ pylori infection.

\section{Statistical analysis}

All statistical analyses were performed using SPSS 11.5 software (SPSS Inc. Chicago, USA). The distribution of variables was tested by "Kolmogorov-Smirnov". The relation between two continuous variables was assessed by Spearman's correlation coefficient. The median of variables was compared between two groups by the Mann-Whitney $U$ test and multiple comparisons by the Kruskal-Wallis test. The receiving operating characteristics (ROC) curve for each evaluation was used to extract the corresponding cut-off point, which can be used to discriminate different histological patterns of patients. For that purpose, the area under each ROC curve was used to measure the discriminatory ability of the model. The resulting value of the cut-off point for each evaluation was applied to the determination of the sensitivity, specificity, positive predictive value (PPV), negative predictive value (NPV), and accuracy of the test. Consequently, 95\% confidence interval was calculated. Different variables influencing the values of PG I, PG II and PG I / II ratio were identified with multivariate logistic regressions adjusted by the histological diagnosis. The value was shown as the median. A two-sided $P$ value of less than 0.05 was considered statistically significant.

\section{RESULTS}

\section{Basic population data on PG levels in Chinese}

Among the 6990 subjects analyzed, the serum levels of PG I and PG II and the PG I / II ratio were significantly skewed from the normal distribution. The median value was $86.9 \mu \mathrm{g} / \mathrm{L}, 10.6 \mu \mathrm{g} / \mathrm{L}$ and $8.1 \mu \mathrm{g} / \mathrm{L}$, respectively.

\section{PG levels in different gender groups}

The gender was significantly correlated with the serum PG I and PG II level $(r=-0.178, r=-0.147, P=0.000)$. The PG I and PG II levels were significantly higher in males than in females, while the PG I / II ratio was significantly lower in males than in females (Table 1).

\section{PG levels in different age groups}

All the objects were assigned to four groups based on their 
Table 1 Serum PG levels in different gender groups (median)

\begin{tabular}{lcccc}
\hline Gender & Cases $(\boldsymbol{n})$ & PG I $(\mu \mathbf{g} / \mathbf{L})$ & PG II $(\mu \mathbf{g} / \mathbf{L})$ & PG I / I \\
\hline Male & 3455 & 95.2 & 12.1 & 7.9 \\
Female & 3535 & 79.7 & 9.4 & 8.3 \\
$P$ value & & 0.000 & 0.000 & 0.000 \\
\hline
\end{tabular}

Table 2 Serum PG levels in different age groups (median)

\begin{tabular}{lcccc}
\hline Age $(\mathbf{y r})$ & Cases $(\boldsymbol{n})$ & PG I $(\boldsymbol{\mu g} / \mathbf{L})$ & PG II $(\mu \mathbf{g} / \mathbf{L})$ & PG I / II \\
\hline A $(\leqslant 40)$ & 1813 & $86.6^{\mathrm{a}}$ & 9.9 & 8.7 \\
B $(41-50)$ & 2225 & $86.9^{\mathrm{b}}$ & $10.6^{\mathrm{d}}$ & $8.3^{\mathrm{f}}$ \\
$\mathrm{C}(51-60)$ & 1840 & $88.6^{\mathrm{c}}$ & $11.3^{\mathrm{e}}$ & $7.8^{\mathrm{g}}$ \\
$\mathrm{D}(\geqslant 61)$ & 1112 & 84.0 & 10.9 & $7.0^{\mathrm{h}}$ \\
\hline
\end{tabular}

PG I : ${ }^{\mathrm{a}} P=0.017,{ }^{\mathrm{b}} P=0.031,{ }^{\mathrm{c}} P=0.019$ vs D group; PG II: ${ }^{\mathrm{d}} P=0.018$ vs $\mathrm{A}$ group, ${ }^{\mathrm{e}} \mathrm{P}=0.010$ vs B group; PG I / II : ${ }^{\mathrm{f}} P=0.003$ vs A group, ${ }^{\mathrm{g}} P=0.002$ vs $\mathrm{B}$ group, ${ }^{\mathrm{h}} P=0.002$ vs $\mathrm{C}$ group.

age: group $\mathrm{A}$ ( $\leqslant 40$ years of age), group $\mathrm{B}(41-50$ years of age), group C (51-60 years of age) and group D ( $\geqslant$ 61 years of age), respectively. The serum PG levels were compared between different groups (Table 2). The serum PG II level increased with age (correlation coefficient: $0.065, P=0.000$ ), while the PG I / II ratio decreased with age (correlation coefficient: $-0.104, P=0.000$ ).

The PG I value increased in groups A $(86.6 \mu \mathrm{g} / \mathrm{L}), \mathrm{B}$ $(86.9 \mu \mathrm{g} / \mathrm{L})$ and $\mathrm{C}(88.6 \mu \mathrm{g} / \mathrm{L})$, though the difference was not significant $(P=0.754, P=0.683$, respectively). The PG I value in group D $(84.0 \mu \mathrm{g} / \mathrm{L})$ was significantly lower than that in groups $\mathrm{C}(P=0.017), \mathrm{B}(P=0.031)$ and $\mathrm{A}$ $(P=0.019)$. The PG II value in groups A $(9.9 \mu \mathrm{g} / \mathrm{L}), \mathrm{B}$ $(10.6 \mu \mathrm{g} / \mathrm{L})$ and $\mathrm{C}(11.3 \mu \mathrm{g} / \mathrm{L})$ increased significantly in the sequence indicated $(P=0.018, P=0.010$, respectively). There was no significant difference in the PG II level between groups $\mathrm{D}(10.9 \mu \mathrm{g} / \mathrm{L})$ and $\mathrm{C}(P=0.803)$. The PG I / II ratio in groups A (8.7), B (8.3), C (7.8) and D (7.0) decreased significantly in the sequence indicated $(P=0.003$, $P=0.002, P=0.002$, respectively ).

\section{PG levels and kinds of gastric disease}

Along the sequence of $\mathrm{NOR} \rightarrow \mathrm{SG} \rightarrow \mathrm{GEU} \rightarrow \mathrm{AG} \rightarrow$ GC groups, the serum PG I and PG II levels increased and then decreased, while the PG I / II ratio decreased gradually. The PG I and PG II levels in the NOR group were lower than those in other groups, while both of them were the highest in GEU. The PG I / II ratio in the NOR group was higher than that other groups, while it was the lowest in the GC group. Several statistical differences were noticed. The differences in the PG II level and the PG I / II ratio between NOR and other groups were of statistical significance. The differences in the PG I / II ratio between SG and other groups were of statistical significance. The differences in PG I and PG II levels in GEU and other groups were of statistical significance. Compared to SG and GEU groups, the differences in PG II level and the PG I / II ratio were of statistical significance in the AG group, while compared to the GC group, the differences in PG, PG II level and the PG I / II ratio had no statistical
Table 3 Serum PG levels in different gastric disease groups (median)

\begin{tabular}{lcccc}
\hline Gastric disease & Cases $(\boldsymbol{n})$ & PG I $(\mu \mathbf{g} / \mathbf{L})$ & PG II $(\mu \mathbf{g} / \mathbf{L})$ & PG I / II \\
\hline NOR & 494 & 79.3 & 7.4 & 10.4 \\
SG & 3654 & 86.0 & 9.4 & 9.0 \\
GEU & 362 & 102.5 & 14.4 & 7.5 \\
SG-IM & 1347 & 89.9 & 12.8 & 6.8 \\
AG & 870 & 84.8 & 13.0 & 6.5 \\
GP & 73 & 87.5 & 13.3 & 6.1 \\
GD & 110 & 96.9 & 15.9 & 5.7 \\
GC & 80 & 84.4 & 11.3 & 6.4 \\
\hline
\end{tabular}

Table 4 Results of Mann-Whitney $\boldsymbol{U}$ test

\begin{tabular}{llll}
\hline \multirow{2}{*}{ Group } & \multicolumn{3}{c}{$\boldsymbol{P}$ value } \\
\cline { 2 - 4 } & PG I & PG II & PG I / II \\
\hline NOR vs SG & 0.000 & 0.000 & 0.000 \\
NOR vs GEU & 0.000 & 0.000 & 0.000 \\
NOR vs AG & 0.021 & 0.000 & 0.000 \\
NOR vs GC & 0.892 & 0.000 & 0.000 \\
SG vs GEU & 0.000 & 0.000 & 0.000 \\
SG vs AG & 0.173 & 0.000 & 0.000 \\
SG vs GC & 0.218 & 0.060 & 0.000 \\
GEU vs AG & 0.000 & 0.017 & 0.002 \\
GEU vs GC & 0.000 & 0.023 & 0.137 \\
AG vs GC & 0.422 & 0.251 & 0.809 \\
\hline
\end{tabular}

significance (Tables 3 and 4).

As described in Table 3, atrophic diseases including AG and GC could be taken as the "low group" (L), and nonatrophic diseases including SG and GEU as the "middle group" (M), and NOR as the "high group" $(\mathrm{H})$. The SGIM could be assigned to the $\mathrm{L}$ group. The argument for the categorization of GP and GD was different. Both of them could be assigned to the $\mathrm{L}$ group too, since the PG I / II ratio decreased along with $A G \rightarrow G C \rightarrow G P \rightarrow G D$, but there was no significant difference between them $(P=$ 0.566). Therefore, the median value of the PG I / II ratio in $\mathrm{H}$ (NOR), $\mathrm{M}$ (SG + GEU) and L (SG - IM + AG + GC + GP + GD) groups was 10.4, 8.8 and 6.6, respectively, while the corresponding differences between neighboring groups were of statistical significance $(P=0.000, P=$ $0.000)$. More interestingly, it was possible to differentiate three histological groups according to their median PG I / II ratio: $>10$ for normal mucosa, $<7$ for atrophic mucosa, and an intermediate value for non-atrophic mucosa.

ROC curves were plotted for each of the serum tests as a predictor of atrophy. The results obtained from the ROC curves could discriminate between patients with atrophy, normal and non-atrophy (Figure 1). The areas under the ROC curves for PG I, PG II, and the PG I / II ratio were $0.494,0.398$ and 0.622 , respectively, suggesting that the PG I / II ratio was the only useful biomarker for screening atrophy in this population. The best cut-off point of the PG I / II ratio for predicting atrophy was 6.9. The corresponding validity parameters were sensitivity $(53.2 \%)$, specificity (67.5\%), PPV (47.3\%), and NPV (72.4\%). The accuracy of the PG I / II ratio as a diagnostic test was $62.4 \%$. 


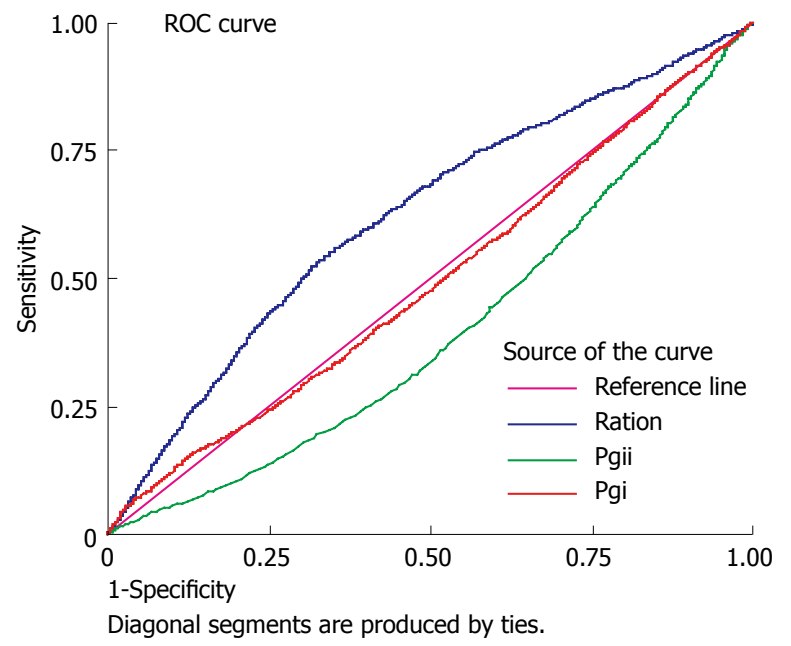

Figure 1 Unadjusted ROC curves for PG I , PG II and the PG I / II ratio to discriminate between patients with atrophic lesions and those with normal or inflammatory gastric mucosa.

\section{PG levels and status of $\mathrm{H}$ pylori infection}

Among the 6990 cases tested, 5285 were positive for $H$ pylori infection and 1705 were negative for $H$ pylori infection. The PG I and PG II levels in the positive group were significantly higher than those in the negative group $(88.7 \mu \mathrm{g} / \mathrm{L} v s 81.4 \mu \mathrm{g} / \mathrm{L}, P=0.000 ; 11.4 \mu \mathrm{g} / \mathrm{L} v s 8.4 \mu \mathrm{g} / \mathrm{L}$, $P=0.000$, respectively), while the PG I / II ratio in the positive group was significantly lower than that in the $H$ pylori group ( 7.7 vs $9.6, P=0.000)$.

\section{Determination of independent variables by multivariable logistic regression}

A multivariable logistic regression was performed to determine the dependent variables that could explain the variation of biomarkers. The applied model took four variables of gender, age ( $<60$ years, $\geqslant 61$ years), gastric mucosal lesion (atrophic or non-atrophic), and $H$ pylori infection $(+,-)$ as inputs and considered the PG I / II ratio $(\leqslant 7,>7)$ as the outcome. Results from this regression gave a statistical significance $\left(\chi^{2}=341.535\right.$, $P=0.000)$. Another qualification for this model was its fitting confidence $(13.695, P=0.250)$. The testing result from this model showed a statistical significance in gender $(P=0.006)$, age $(P=0.000)$, atrophic lesion $(P=0.000)$ and $H$ pylori infection $(P=0.000)$. Their corresponding risk factors were male (OR: 1.151, 95\% CI: 1.042-1.272), age $\geqslant 61$ years (OR: $1.358,95 \%$ CI: 1.188-1.553), atrophic lesion (OR: 2.075, 95\% CI: 1.870-2.302) and H pylori infection (OR: 1.546, 95\% CI: 1.368-1.748) (Table 5). The overall accordance of this model was $64.6 \%$.

\section{DISCUSSION}

In this study, we reported for the first time the essential serum PG levels in the Chinese population, including some influence influencing factors such as sex, age, the presence of gastric diseases, and $H$ pylori infection.

Studies have reported some conflicting results with regard to the correlation between serum PG level and
Table 5 Multivariable logistic regression of the Pg I / II ratio

\begin{tabular}{|c|c|c|c|c|}
\hline & $n$ & Coeff. & $95 \% \mathrm{CI}$ & $\boldsymbol{P}$-values \\
\hline \multicolumn{5}{|l|}{ Gender } \\
\hline Female & 3535 & Baseline & & \\
\hline Male & 3455 & 1.151 & $1.042-1.272$ & 0.006 \\
\hline \multicolumn{5}{|l|}{ Age } \\
\hline$<60 \mathrm{yr}$ & 5878 & Baseline & & \\
\hline$\geqslant 61 \mathrm{yr}$ & 1112 & 1.358 & $1.188-1.553$ & 0.000 \\
\hline \multicolumn{5}{|c|}{ Gastric mucosal lesions } \\
\hline Non-atrophy & 4510 & Baseline & & \\
\hline Atrophy & 2480 & 2.075 & $1.870-2.302$ & 0.000 \\
\hline \multicolumn{5}{|l|}{ H pylori } \\
\hline H pylori ${ }^{-}$ & 1705 & Baseline & & \\
\hline H pylori $^{+}$ & 5285 & 1.546 & $1.368-1.748$ & 0.000 \\
\hline
\end{tabular}

age or sex. For instance, men have higher normal PG I values than women ${ }^{[18]}$, which is in agreement with the data on blood donors ${ }^{[19]}$. In contrast, in 20-70 year old Japanese, serum PG level is dependent on the age and PG I increases gradually with age, while the PG I / PG II ratio decreases significantly ${ }^{[20]}$. In our study, the PG I and PG II levels were significantly higher in males than in females. The PG I / II ratio of the males was significantly lower than that of the females. Both PG I and PG II levels increased gradually till the age of 60 years, while the PG I / II ratio showed a significant stage reduction. These findings are in agreement with the reported data ${ }^{[0]}$. These different age-dependences therefore require a thorough checking of the characteristically different distribution, and difference among populations in application value for serum PG. Another important aspect needing special attention is the identification of its normal distribution in different age and gender groups by stratification.

Serum PG is a well-known indicator and "serological biopsy" of corpus mucosa ${ }^{[21,22]}$. A cascade of mucosal lesions, from chronic gastritis, atrophy, intestinal metaplasia, to dysplasia has been consistently identified, at least for Lauren's intestinal subtype of $\mathrm{GC}^{[23]}$. In this study, along with the sequence of $\mathrm{NOR} \rightarrow \mathrm{SG} \rightarrow \mathrm{GEU} \rightarrow \mathrm{AG} \rightarrow$ GC, the serum PG I and PG II levels increased while the PG I / II ratio decreased. When it came to the atrophic lesion from the non-atrophic lesion, both PG I and PG II levels had a trend to go down, suggesting that the PG I / II ratio reflects the development of atrophic lesion on gastric membranes better than either PG I or PG II alone. The PG I / II values for atrophic gastritis were significantly lower than those for NOR and non-atrophic lesions, while there was no difference among these atrophic lesions, suggesting that the PG I / II ratio is an effective parameter for screening individuals at high risk of $\mathrm{GC}^{[0,24-27]}$. We obtained the best cut-off points of the PG I / II ratio for detecting GC and its precursors by ROC curve with a sensitivity of $53.2 \%$ and a specialty of $67.5 \%$, which can be used for further investigation as a screening tool in the first period.

H pylori infection frequently persists lifelong in the host stomach and is associated with a wide spectrum of human gastric and duodenal diseases, ranging from gastritis to duodenal ulcer, GC and MALT lymphoma ${ }^{[28,29]}$. In 1994, it was defined as a definite carcinogen by the International 
Agency for Research on Cancer ${ }^{[30]}$. It was reported that $H$ pylori stimulates $\mathrm{G}$ cells in the antrum, thus increasing the level of gastrin they secreted ${ }^{[31]}$. Gastrin directly stimulates the main cells and is able to stimulate the synthesis and secretion of PGs, especially PG II by increasing the density of calcium-ion flux, cAMP and phosphoinositide inside the main cells. Serum epidemiological studies showed that $H$ pylori infection correlates significantly to the elevated serum PG especially PG II, and the reduced PG I / II ratio $^{[32]}$. Our previous study revealed that the incidence of $H$ pylori infection is $79.3 \%$ in Zhuanghe County ${ }^{[33]}$. In the present study, the serum PG I and II levels in positive $H$ pylori individuals were significantly higher than those in negative $H$ pylori individuals, and the PG I / II ratio was lower in positive $H$ pylori individuals than in negative $H$ pylori individuals, confirming that $H$ pylori infection influences the serum PG level in residents of Zhuanghe County.

Multivariable logistic regression with the PG I / II ratio as the outcome showed that the PG I / II levels were significantly affected if the surveyed samples met any one of the following qualifications: male, age $>60$ years, atrophic lesion and $H$ pylori infection, showing that all these factors should be taken into account in the screening of GC with serum PGs.

In summary, our results from this population-based study provide the essential characteristics of serum PG in Chinese. The PG I / II ratio is more suitable for identifying subgroups with different influencing factors, compared with PG I or PG II alone. This implies that low PG I / II ratio can be used as a serological indicator of gastric atrophic diseases.

\section{COMMENTS}

\section{Background}

Human pepsinogens (PGs) are inactive pro-enzymes for the specific digestive enzyme--pepsin originating from the gastric mucosa, and can be classified biochemically and immunochemically into pepsinogen I (PG I ) and pepsinogen II (PG II). Serum PG levels are related to the morphologic and functional changes in the stomach, and can be used as a 'serological biopsy'.

\section{Research frontiers}

In the present study, we investigated the essential characteristics of serum PG in Chinese, which provides a valuable reference for large-scale surveys of gastric cancer in China.

\section{Innovations and breakthroughs}

In this study, we analyzed the essential characteristics of serum PG levels and their influencing factors in residents from the Zhuanghe County in North China. Our results that serum PG skewed from the normal distribution significantly, and was influenced by age, sex, the gastric mucosa lesions and $H$ pylori infection. The PG I / II ratio was more suitable for identifying subgroups with different influencing factors, compared with PG I or PG II alone.

\section{Applications}

The essential characteristics of serum PG in Chinese are described. The PG I / II ratio is more suitable for identifying subgroups with different influence factors and can be used as a serological indicator of gastric atrophic diseases.

\section{Peer review}

This paper presents the serum pepsinogen values and their influencing factors in a large group of Chinese from North China, which is of certain importance. However, a large room for improvement in its language.

\section{REFERENCES}

1 Gritti I, Banfi G, Roi GS. Pepsinogens: physiology, pharmacology pathophysiology and exercise. Pharmacol Res 2000; 41: 265-281

2 Kageyama T. Pepsinogens, progastricsins, and prochymosins: structure, function, evolution, and development. Cell Mol Life Sci 2002; 59: 288-306

3 Samloff IM. Pepsinogens I and II: purification from gastric mucosa and radioimmunoassay in serum. Gastroenterology 1982; 82: 26-33

4 Samloff IM, Varis K, Ihamaki T, Siurala M, Rotter JI. Relationships among serum pepsinogen I, serum pepsinogen II, and gastric mucosal histology. A study in relatives of patients with pernicious anemia. Gastroenterology 1982; 83: 204-209

5 Samloff IM, Taggart RT. Pepsinogens, pepsins, and peptic ulcer. Clin Invest Med 1987; 10: 215-221

6 Sipponen $\mathrm{P}$, Härkönen $\mathrm{M}$, Alanko A, Suovaniemi O. Diagnosis of atrophic gastritis from a serum sample. Minerva Gastroenterol Dietol 2003; 49: 11-21

7 Väänänen $\mathbf{H}$, Vauhkonen $M$, Helske $T$, Kääriäinen $I$, Rasmussen M, Tunturi-Hihnala H, Koskenpato J, Sotka M, Turunen M, Sandström R, Ristikankare M, Jussila A, Sipponen P. Non-endoscopic diagnosis of atrophic gastritis with a blood test. Correlation between gastric histology and serum levels of gastrin-17 and pepsinogen I: a multicentre study. Eur J Gastroenterol Hepatol 2003;15: 885-891

8 Miki K, Morita M, Sasajima M, Hoshina R, Kanda E, Urita Y. Usefulness of gastric cancer screening using the serum pepsinogen test method. Am J Gastroenterol 2003; 98: 735-739

9 Mukoubayashi C, Yanaoka K, Ohata H, Arii K, Tamai H, Oka M, Ichinose M. Serum pepsinogen and gastric cancer screening. Intern Med 2007; 46: 261-266

10 Ohata H, Oka M, Yanaoka K, Shimizu Y, Mukoubayashi C, Mugitani K, Iwane M, Nakamura H, Tamai H, Arii K, Nakata H, Yoshimura N, Takeshita T, Miki K, Mohara O, Ichinose M. Gastric cancer screening of a high-risk population in Japan using serum pepsinogen and barium digital radiography. Cancer Sci 2005; 96: 713-720

11 Miki K. Gastric cancer screening using the serum pepsinogen test method. Gastric Cancer 2006; 9: 245-253

12 Dinis-Ribeiro M, Yamaki G, Miki K, Costa-Pereira A, Matsukawa M, Kurihara M. Meta-analysis on the validity of pepsinogen test for gastric carcinoma, dysplasia or chronic atrophic gastritis screening. J Med Screen 2004; 11: 141-147

13 Checchi S, Montanaro A, Pasqui L, Ciuoli C, Cevenini G, Sestini F, Fioravanti C, Pacini F. Serum ghrelin as a marker of atrophic body gastritis in patients with parietal cell antibodies. J Clin Endocrinol Metab 2007; 92: 4346-4351

14 Zhang XH, Zhao WY, Sun XM, Bu YH, Yan X, Wang JL, Wang HY, Zhang ZG, Mi JM, Xie TX, San JSY, Qing MYX, Wang F. Radioimmunological Analysis on Serum Pepsiogen and Gastrin of Rural Adult Residents in High Risk Area of Gastric Cancer . Zhongguo Gonggong Weisheng 2002; 18: 287-288

15 Yuan Y. Comprehensive Prevention and Treatment for High Risk Population in High Risk Area With Gastric Cancer in Zhuanghe Region, Liaoning Province. Zhongguo Zhongliu 2005; 14: 307-311

16 Lin SR, Yu ZL, Hu PJ, Wang CW, Xu GM, Xiao SD, Shi R, Liu WZ. Consensus on chronic gastritis formulated at the national symposium. Zhonghua Xiaohua Zazhi 2000; 20: 199-201

17 Dixon MF, Genta RM, Yardley JH, Correa P. Classification and grading of gastritis. The updated Sydney System. International Workshop on the Histopathology of Gastritis, Houston 1994. Am J Surg Pathol 1996; 20: 1161-1181

18 Hokkanen S, Kosunen TU, Sarna S, Miettinen A, Salomaa A Aromaa A, Knekt P, Rautelin HI. Normal serum pepsinogen I levels in adults: a population-based study with special reference to Helicobacter pylori infection and parietal cell antibodies. Scand J Clin Lab Invest 2005; 65: 291-299

19 Veenendaal RA, Biemond I, Peña AS, van Duijn W, Kreuning J, Lamers CB. Influence of age and Helicobacter pylori infection on serum pepsinogens in healthy blood transfusion donors. 
Gut 1992; 33: 452-455

20 Aoki K, Misumi J, Kimura T, Zhao W, Xie T. Evaluation of cutoff levels for screening of gastric cancer using serum pepsinogens and distributions of levels of serum pepsinogen I, II and of PG I/PG II ratios in a gastric cancer case-control study. J Epidemiol 1997; 7: 143-151

21 Korstanje A, den Hartog G, Biemond I, Lamers CB. The serological gastric biopsy: a non-endoscopical diagnostic approach in management of the dyspeptic patient: significance for primary care based on a survey of the literature. Scand J Gastroenterol Suppl 2002; 22-26

22 Di Mario F, Moussa AM, Caruana P, Merli R, Cavallaro LG, Cavestro GM, Dal Bò N, Iori V, Pilotto A, Leandro G, Franzè A, Rugge M.'Serological biopsy' in first-degree relatives of patients with gastric cancer affected by Helicobacter pylori infection. Scand J Gastroenterol 2003; 38: 1223-1227

23 Correa P. Human gastric carcinogenesis: a multistep and multifactorial process--First American Cancer Society Award Lecture on Cancer Epidemiology and Prevention. Cancer Res 1992; 52: 6735-6740

24 Miki K, Sasajima M, Ohtsuka T, Urita Y. [Pepsinogen I, pepsinogen II, and pepsinogen I/II ratio]. Nihon Rinsho 2005; 63 Suppl 8: 741-743

25 Miki K, Urita Y. Using serum pepsinogens wisely in a clinical practice. J Dig Dis 2007; 8: 8-14

26 Kato M, Asaka M, Shimizu Y, Nobuta A, Takeda H, Sugiyama T. Relationship between Helicobacter pylori infection and the prevalence, site and histological type of gastric cancer. Aliment Pharmacol Ther 2004; 20 Suppl 1: 85-89
27 Lee YC, Lin JT, Wu HM, Liu TY, Yen MF, Chiu HM, Wang HP, Wu MS, Hsiu-Hsi Chen T. Cost-effectiveness analysis between primary and secondary preventive strategies for gastric cancer. Cancer Epidemiol Biomarkers Prev 2007; 16: 875-885

28 Broutet N, Plebani M, Sakarovitch C, Sipponen P, Mégraud F. Pepsinogen A, pepsinogen $C$, and gastrin as markers of atrophic chronic gastritis in European dyspeptics. $\mathrm{Br} J$ Cancer 2003; 88: $1239-1247$

29 Ernst PB, Peura DA, Crowe SE. The translation of Helicobacter pylori basic research to patient care. Gastroenterology 2006; 130 188-206; quiz 212-3

30 International Agency for Research on Cancer. Schistosomes, live flukes and Helicobacter pylori. LARC monographs on the evaluation on carcinogenic risks to humans. Vo161. Lyon: LARC, 1994: 177-240

31 Lorente S, Doiz O, Trinidad Serrano M, Castillo J, Lanas A. Helicobacter pylori stimulates pepsinogen secretion from isolated human peptic cells. Gut 2002; 50: 13-18

32 Ohkusa T, Miwa H, Nomura T, Asaoka D, Kurosawa A, Sakamoto N, Abe S, Hojo M, Terai T, Ogihara T, Sato N. Improvement in serum pepsinogens and gastrin in longterm monitoring after eradication of Helicobacter pylori: comparison with H. pylori-negative patients. Aliment Pharmacol Ther 2004; 20 Suppl 1: 25-32

33 Lin HZ, Yuan Y, Zhang GF, Gao H, Bai XW. Campylobacterpyloridis infection of gastric mucosa in the high and low risk areas of stomach cancer in China. Zhongguo Aizheng Yanjiu 1993; 5: 101-104

S- Editor Liu Y L- Editor Wang XL E- Editor Li HY 